\title{
Perception and practices during the COVID-19 pandemic in an urban community in Nigeria: A Cross-sectional Study
}

\author{
Olayinka Ilesanmi ${ }^{\text {Corresp., } 1,2}$, Aanuoluwapo Afolabi ${ }^{1}$ \\ ${ }^{1}$ Department of Community Medicine, University of Ibadan, Ibadan, Oyo State, Nigeria \\ 2 Department of Community Medicine, University College Hospital, Ibadan, Oyo State, Nigeria \\ Corresponding Author: Olayinka llesanmi \\ Email address: ileolasteve@yahoo.co.uk
}

BACKGROUND. Various perceptions and practices have been associated with the COVID-19 pandemic. In this study, we assessed the perception and practices regarding COVID-19 among residents in selected urban communities of Ibadan, Oyo State, Nigeria.

METHODS. A descriptive cross-sectional study design using a multi-stage sampling technique was used to recruit 360 respondents (Mean age: $33.2 \pm 10.6$ years; $62.5 \%$ females) from households in Ibadan. Data were collected using an interviewer-administered questionnaire from 3rd - 6th June 2020. Those who demonstrated washing of the palm, back of the hand, spaces between the fingers, fingernails, wrist, and thumbs had 6 points and were categorized to have had a good practice of handwashing. Descriptive statistics were conducted. Bivariate analyses of sociodemographic characteristics and good hand washing practices were conducted using Chi-square test. Logistic regression was conducted to identify the determinants of good handwashing practices. P-values $<0.05$ were statistically significant.

RESULTS. Going to the hospital (95\%) and calling the COVID-19 help number (58.3\%) were the frequently reported practices among respondents following the development of COVID-19 symptoms. Also, 89 (26\%) knew they could contract COVID-19, while 41 (12\%) perceived it as an exaggerated event. The effects most frequently reported by respondents were hunger/low income $(48.8 \%)$ and academic delay (8.8\%). Use of face masks by $64.5 \%$ and social distancing $(48 \%)$ were the most frequently reported practices for prevention. Only $71(20.8 \%)$ demonstrated good handwashing practices. The perception of likelihood to contract COVID-19 and practices to prevent COVID-19 had a weak correlation of $0.239(p<0.001)$.

CONCLUSION. Gaps exist in the practices that prevent COVID-19. There is a need to improve handwashing, use of face masks and other practices that prevent COVID-19. Implications across public health communication and policies were stated. 


\section{Perception and practices during the COVID-19 pandemic}

\section{3 in an urban community in Nigeria: A Cross-sectional Study}

4

5 Olayinka S. Ilesanmi ${ }^{1,2}$, Aanuoluwapo A. Afolabi ${ }^{1}$

$6{ }^{1}$ Department of Community Medicine, University of Ibadan, Oyo State, Nigeria

72 Department of Community Medicine, University College Hospital, Ibadan, 8

9 Corresponding Author:

10

Olayinka Ilesanmi, Department of Community Medicine, University of Ibadan, Oyo State, Nigeria

Email address: E mail: ileolasteve@yahoo.co.uk

Phone: +2348032121868

\section{Abstract}

\section{BACKGROUND.}

Various perceptions, and practices have been associated with the COVID-19 pandemic. In this study, we assessed the perception and practices regarding COVID-19 among residents in selected urban communities of Ibadan, Oyo State, Nigeria.

\section{METHODS.}

A descriptive cross-sectional study design using a multi-stage sampling technique was used to recruit 360 respondents (Mean age: $33.2 \pm 10.6$ years; 62.5\% females) from households in Ibadan. Data were collected using an interviewer-administered questionnaire from 3rd - 6th June 2020. Those who demonstrated washing of the palm, back of the hand, spaces between the fingers, fingernails, wrist, and thumbs had 6 points and were categorized to have had a good practice of handwashing. Descriptive statistics were conducted. Bivariate analyses of sociodemographic characteristics and good hand washing practices were conducted using Chi- 
30 square test. Logistic regression was conducted to identify the determinants of good handwashing 31 practices. P-values $<0.05$ were statistically significant.

\section{RESULTS.}

34 Going to the hospital (95\%) and calling the COVID-19 help number (58.3\%) were the frequently reported practices among respondents following the development of COVID-19 symptoms. Also, $89(26 \%)$ knew they could contract COVID-19, while $41(12 \%)$ perceived it as an exaggerated event. The effects most frequently reported by respondents were hunger/low income (48.8\%) and academic delay (8.8\%). Use of face masks by $64.5 \%$ and social distancing (48\%) were the most frequently reported practices for prevention. Only 71(20.8\%) demonstrated good handwashing practices. The perception of likelihood to contract COVID-19 and practices to prevent COVID19 had a weak correlation of $0.239(\mathrm{p}<0.001)$.

42

\section{CONCLUSION.}

44 Gaps exist in the practices that prevent COVID-19. There is a need to improve handwashing, use of face masks and other practices that prevent COVID-19. Implications across public health communication and policies were stated.

Keywords: Coronavirus, COVID-19, risk perception, handwashing practices, Nigeria.

\section{Introduction}

51

52 The Coronavirus infection (COVID-19) is an emerging infectious illness which broke out during 53 the winter of 2019 (Al-Hanawi et al, 2020; WHO, 2020). Due to its presentations, it has been 54 declared a public health emergency of international concern by the World Health Organization 55 (WHO) (WHO, 2020). An alarming response has been introduced across the globe due to its 56 high infectiousness and case fatality rate (Zhong et al., 2020). The identification of the risks and 57 the prevention of infectivity regarding COVID-19 have been stated to depend on human 58 perception (Zhong et al., 2020). Especially in the submergence of an infectious disease such as 59 COVID-19, different thoughts have shaped individuals' views on the illness. 
61 Currently, the Coronavirus disease has spread to 213 countries with nearly 24 million confirmed 62 cases with close to 820,000 recorded deaths (WHO, 2020). Publicly available reports from the 63 64 65 66

79

80

81

82 Africa Centre for Disease Control (ACDC) states that confirmed cases of COVID-19 had risen to $1,203,769$ and 28,289 deaths as of 25th of August 2020 (ACDC, 2020). As of 25th of August 2020, the West African subregion accounted for a significant proportion of cumulative COVID19 records in Africa. In Nigeria, there are 52,800 confirmed cases of COVID-19 with a total of 1007 deaths as of 25th of August 2020 (NCDC, 2020; WHO, 2020). Oyo State presently holds the third spot on the Nigeria Centre for Disease Control (NCDC) daily COVID-19 updates, with 3058 laboratory-confirmed cases of COVID-19 and 37 deaths (NCDC, 2020). Urban areas in Ibadan, the capital city of Oyo State frequently present with confirmed cases (Enwongo, 2020).

As a part of the emergency response activities across all States in Nigeria, health education campaigns have been directed at members of the public (NCDC, 2020). These campaigns have been aimed at knowledge improvement and the correction of certain misconceptions that have been widely circulated among community members (NCDC, 2020) Education on precautionary measures such as wearing of face masks, regular handwashing with soap and water or with alcohol-based hand sanitizers, and social distancing have been done (NCDC, 2020; The Pace Setter State, 2020).

It is evident that perception shapes one's knowledge and the adoption of safety measures concerning the transmission of an infection. Data obtained from the perception of community members regarding COVID-19 could help target interventions needed to improve the knowledge of community members regarding Coronavirus. Superstitious beliefs have largely shaped the perception of most Nigerians regarding the source and cause of COVID-19 (Chukwuorji \& Iorfa, 2020). At the onset of the COVID-19 outbreak in Nigeria, infected persons belonged to either the political class or high socioeconomic cadre (Chukwuorji \& Iorfa, 2020). The characteristic prevalence of COVID-19 infection among this group of persons accorded COVID-19 the name, 'a disease of the rich and mighty' (Nwaubani, 2020). Few months into the COVID-19 outbreak in Nigeria, perceptions revolved around "immunity" to COVID-19 among the religious folks with a disregard of bans on religious gatherings (Lichtensein, Ajayi, \& Egbunike, 2020). Such perceptions could have been influenced by several factors. Social media platforms such as 
92 WhatsApp, Facebook, and Twitter have been used to spread false news on COVID-19, resulting 93 to panic disorder and anxiety among some persons and shunning of safety measures among 94 others (Aluh \& Onu, 2020; Olapegba et al., 2020). Among many persons, physical distancing, 95 social isolations, restriction of religious and social gatherings etc. have been opined as alien 96 solutions in overcoming the COVID-19 pandemic in Nigeria and Africa at large (Olapegba et al., 97 2020).

98

99 Literatures have reported the existence of knowledge relating to COVID-19 among Nigerians, 100 and it is expected that this would influence precautionary behavior among them. However, 101 inherent wrong perceptions may contribute to COVID-19 risk aversion measures (Iorfa et al., 102 2020). Perceptions of COVID-19 has been influenced by age and gender. Due to their increased 103 vulnerability to illnesses, older persons have been predicted to increasingly adopt COVID-19 104 precautionary behavior compared to other population groups (Iorfa et al., 2020). Females have 105 been identified as models in the adoption of precautionary health behavior. In the COVID-19 106 context, the practice of handwashing, hygiene, and use of face masks occur more frequently 107 among females than males (Iorfa et al., 2020). Such an occurrence could be due to the perceived 108 susceptibility to illnesses among females as well as their health-conscious nature.

109

110

111

112

113

114

115

116

117

118

119

120

121

122

Given the importance of risk perception in behavior modification for disease control, it becomes pertinent to assess the perception and practices regarding COVID-19. To the best of our knowledge, the perception, and practices of community members in urban areas in Ibadan regarding COVID-19 is currently unknown. An assessment of the perception and practices of community members is important to reduce the risk for COVID-19 infection in Ibadan, a densely populated city in Nigeria. We hypothesized that there is no difference in the sociodemographic characteristics of the community members with the practices of COVID-19 mitigating factors. This study thus aimed at assessing the perception and practices of community members in urban areas in Ibadan regarding COVID-19. 


\section{Materials \& Methods}

126

Study design and study setting

127

128

A descriptive cross-sectional study design was used. Data was collected using an interviewer129 administered questionnaire. Data collection took place from the 3rd of June to the 6th of June 2020. The study was carried out in Ibadan, Oyo State Nigeria. Ibadan is the capital city of Oyo State. Oyo State is one of the states in the south western part of Nigeria. Between 15th of June and 10th of August, 2020, confirmed COVID-19 cases had risen from 764 to 2,887 in Oyo State, and the State ranks next to Lagos State and the Federal Capital Territory on the NCDC reports for COVID-19 (NCDC, 2020; Enwongo, 2020). The official language in Nigeria is English, while the major informal language for communication in Ibadan is Yoruba, which has different dialects.

\section{Study population}

The study population for the survey was one eligible member of the households in the selected urban communities in Ibadan, Oyo State. All consenting household members were included in the study. Household members that were less than 18 years were excluded. Verbal consent was obtained from participants.

Sample size determination and sampling technique

146

The sample size was calculated using sample size formula for descriptive cross-sectional study.

148 The population of the selected LGA is $>100,000$. The sample size was calculated using the 149 Leslie Kish formula for sample size determination for a single proportion as follows:

$150 \mathrm{n}=\mathrm{Z} \alpha^{2} \mathrm{p}(1-\mathrm{p}) / \mathrm{d}^{2}$ where:

$151 \mathrm{n}=$ Minimum desired sample size

$152 \mathrm{Z}=$ the standard normal deviate, usually set as 1.96 which corresponds to $5 \%$ level of 153 significance. 
$154 \mathrm{P}=50 \%$ was be used

$155 \mathrm{~d}=$ Degree of accuracy (precision) set at $5 \%(0.05)$

$156 \mathrm{n}=1.96^{2} \times 0.5 \mathrm{x}(1-0.5) / 0.05^{2}=384$

157 A sample of $360(93.8 \%)$ were studied in the urban communities of Ibadan. A multi-stage

158 sampling technique was used to select the respondents for the study

159

160 Stage 1:

161 Simple random sampling was used to select 3 out of the 6 urban local government area in Ibadan. 162

163 Stage 2:

164

In each of the selected LGA, a political ward was chosen for the study. 165

166 Stage 3:

A center location was chosen in the selected ward. A bottle was rotated to determine the 168 direction of movement of the interviewers. From the direction of the bottle tip all consenting 169 eligible adults from the households were included in the study until 120 persons were 170 interviewed in each LGA.

171 Sampling of 120 each in the three urban LGA gives a total sample size of 360.

172

173 Data Collection Methods

174

175 The questionnaire has two sections.

176 Section A: Sociodemographic characteristics

177 The sociodemographic characteristics include age of respondents, sex, highest level of education, 178 ethnicity, and occupation.

179

180 Section B: Perception and practices regarding COVID-19.

181 Close-ended questions were asked on perception of the respondents on COVID-19, their current 182 practices, and what they would do if they were infected. Open-ended questions were asked on 183 the effects of COVID-19 on and suggestions to the government to curb the pandemic. 
185 A six-point question was asked on the practice of handwashing. The respondents were asked to 186 demonstrate how they usually practice handwashing. The interviewer correctly marked all the 187 points demonstrated by respondents.

188

189 The questionnaire was adapted from a tool used for a similar perception study on Ebola Virus 190 Disease in 2014 (Gidado et al., 2014). The tool was validated by an infectious disease 191 epidemiologist. Pre-testing of the tool was done by administering 10 questionnaires in another 192 Local Government Area not selected for the study. A few ambiguous questions were modified. 193 Back-to-back translation of the questionnaire was done by experts who had sound understanding 194 of the Yoruba language. The questionnaire was administered to most of the respondents in 195 Yoruba Language. Data collection was done by trained research assistants with a minimum of 196 first degree.

197

198

Independent variables included: Sociodemographic characteristics like age, sex, level of 199 education, and occupation.

200 Outcome/dependent variables were the practice of handwashing and the use of other mitigating 201 measures.

202

203

Data Management

204

205 Data were analyzed with SPSS version 23. Age was summarized using mean and standard 206 deviation, while frequencies, and percentages were used for categorical variables. A total score 207 of 6 was assigned to good practice of hand washing after the respondents were asked to 208 demonstrate hand washing. One point each was assigned for the following: palm, back of the 209 hand, spaces between the fingers, fingernails, wrist and thumbs. Only those who demonstrated 210 the 6 points were categorized to have had a good practice of handwashing. Chi square test was 211 used for the assessment of associations between sociodemographic characteristics and practice of 212 handwashing. Pearson correlation was conducted between the perception of the likelihood of 213 contracting COVID-19 and practices to prevent COVID-19. Multivariate analysis of the 214 determinants of good handwashing practices was conducted using Logistic regression. P-values $215<0.05$ were accepted as significant. 
216

\section{Ethical Approval and Consent to Participate}

218

219 Ethical approval to carry out the study was obtained from the Oyo State Ministry of Health 220 Ethical Review Committee, with reference number AD/13/479/1779A . Permission for the study 221 was sought from the respondents and their confidentiality was ensured. The respondents were 222 informed of their right to decline or withdraw from the study at any time without any adverse 223 consequences. No harm came to participants because of participation in this study.

224

225

\section{Results}

226

227

A total of 360 respondents were interviewed among urban residents in Ibadan. The mean age was 228 $33.2 \pm 10.6$ years, and $225(62.5 \%)$ were females. Those with secondary education and above were $332(92.2 \%), 314(87.2 \%)$ were of the Yoruba ethnic group, and $171(47.5 \%)$ engaged in 230 business or trading. (Table 1). Among the 360 respondents 342 (95\%) have heard of COVID-19.

231

232

Most frequently reported practices among respondents following the development of COVID-19 233 symptoms were: Going to the hospital 171(50\%) and calling the COVID-19 help number 105

234 (30.7\%). The other reported practices included: Praying and staying at home each with 29 (8.5\%) respondents as shown in Figure 1.

236

237 Regarding COVID-19, 89 (26\%) knew they could contract COVID-19, while 41 (12\%) 238 perceived it as an exaggerated event. It was also perceived as an intention for corruption by 23 239 (6.7\%), COVID-19 was an attack by the Western World was reported by 68 (19,9\%), and 240 122(35.7\%) called COVID-19 a source of panic. The effects most frequently reported by 241 respondents were hunger/low income 167 (48.8\%) and academic delay 30 (8.8\%). Regarding 242 suggestions to the government, 108 (31.6\%) suggested the provision of medical 243 supplies/palliatives/ seeking of cure, while 68 (19.9\%) suggested free testing/free treatment. 244 Other effects of COVID-19 and suggestions to the government are as shown in Table 2. 
246 The most frequently reported practice for prevention of COVID-19 among respondents were the 247 use of face masks by $224(65.5 \%)$ and social distancing by 164 (48\%). Others included: Staying 248 at home/following COVID-19 updates 8 (2.2\%), taking Vitamin C/fruits/warm water 4 (1.1\%), 249 and doing nothing $5(1.4 \%)$ as shown in Figure 2.

250

251 Figure 3 shows that only $80(22 \%)$ of respondents demonstrated good handwashing practices. 252 Among respondents aged less than 25 years, 16 (23.5\%) had good handwashing practice 253 compared to $14(29.8 \%)$ aged above 45 years. Among females, 49 (22.8\%) had good 254 handwashing practices compared to 22(17.3\%) males although these differences are not 255 statistically significant (Table 3).

256

257

Males have $27.5 \%$ less odds of having good hand washing practice compared to females, though

258 not statistically significant [AOR 0.725,95\% $\mathrm{CI}=0.418-1.259, \mathrm{p}=0.253$ ] (Table 4).

259

260 The perception of the likelihood to contract COVID-19 and practices to prevent COVID-19 had 261 a weak positive correlation of $0.239(\mathrm{p}<0.001)$.

262

263

\section{Discussion}

264

265 This study found that many individuals lived in denial of the existence of COVID-19. The 266 perception of the illness as an avenue for politicians to enrich themselves indicates that there still 267 exists inadequate knowledge of the Coronavirus among community members in Ibadan. Denial, 268 ignorance regarding COVID-19, and the existing lack of trust in the Nigerian government have 269 been reported since the outbreak of COVID-19 in Nigeria (Chukwuorji \& Iorfa, 2020). From the 270 present study, a high rating of the perceived likelihood of contracting COVID-19 was observed 271 among $26 \%$ of respondents, while it was minimally perceived as an attack by the Western World 272 among nearly $20 \%$.

273

274 Findings obtained from this study revealed that the practices most often adopted following the 275 development of COVID-19 symptoms were either to go to the hospital or call the COVID-19 276 help number. This indicates that the source of help for COVID-19 treatment is well known 
277 among community members in urban areas of Ibadan. Although distrust in government capacity 278 regarding COVID-19 is currently obtained, individuals are willing to take proactive measures 279 following the suspected development of COVID-19 symptoms (Chukuorji \& Iorfa, 2020). An 280 Indian study similarly reported that hospital visitation was frequently opted for as a step to be 281 taken following the development of COVID-19 in individuals in a close relationship (Dkar et al., 282 2020).

283

284 We found that the use of face masks and practice of social distancing measures were more 285 frequently embraced among respondents compared to other COVID-19 mitigation measures, 286 although full adherence was low. A web-based study conducted in Nigeria mostly stated mouth287 covering while sneezing, wearing of face masks, and avoidance of crowded spaces as self288 reported practices among respondents (Iorfa et al., 2020). Our findings revealed that myriads of 289 perceptions were associated with COVID-19. These included COVID-19 as an exaggerated illness with intentions for corruption, its highly infectious and deadly nature, and a reason for panic disorders. Similarly, the likelihood of positive practices concerning COVID-19 was 292 associated with a positive perception of the risk of infection (Zhong et al., 2020). Findings from 293 previous studies conducted in Nigeria also corroborate the key role of positive risk perception on imbibing COVID-19 protective practices and attitudes (Iorfa et al., 2020). The finding from the present study contradicts the assumption of the Health Belief Model (HBM) that protective 296 actions are more likely to succeed a high level of perceived susceptibility (Tarkang et al., 2015). The results obtained herein is higher than the knowledge concerning the practice of face masks in Saudi Arabia (Al-Hanawi et al., 2020). Due to its deadly nature, COVID-19 has introduced fear which has compelled protective actions from individuals regarding the illness (Zhong et al., 300 2020).

301

302 Previous studies have shown that fear could motivate healthy behavior among individuals 303 especially during epidemics, but such behavior may not be sustainable (Witte, 1998; Nabi, 1999; 304 Ufuwa et al., 2020). The adoption of these healthy behaviors in the present study is in tandem 305 with the recommendations of the World Health Organization (WHO) on safety measures for 306 COVID-19 (WHO, 2020). The insufficiency of fear as a propellant for adherence to 307 recommended guidelines for COVID-19 has been reported to be an outplay of knowledge- 
308 attitude discrepancy (Iorfa et al., 2020). These findings imply that individual perception of 309 infectious illnesses such as COVID-19 may not be sufficient to influence the adoption of 310 protective practices. This explains the need for a regular sensitization of community members on 311 COVID-19 safety measures regardless of their perception concerning the illness.

312

313 We found that the practice of handwashing was commoner among individuals with a greater risk 314 perception for COVID-19. Because these individuals perceive themselves as vulnerable to 315 COVID-19 infection, they are more likely to engage in handwashing practice. Handwashing 316 practice has been identified as one of the mitigation strategies for breaking the chain of COVID-

31719 transmission. An online-based Nigerian survey revealed a higher practice of handwashing 318 compared to other COVID-19 preventive measures (Iorfa et al., 2020). A study conducted in 319 Ibadan on hand hygiene practices post Ebola virus disease outbreak revealed a high proportion of 320 inadequate self-reported hand hygiene practice (Martins \& Osiyemi, 2017). Lassa fever studies 321 conducted in Edo State reported inadequate handwashing practices, while a similar study in 322 Kaduna State, Nigeria reported good handwashing practices among respondents (Tobin et al., 323 2019;). The similarities of most of these findings with ours imply the wide acceptance of the 324 practice of handwashing in the management of infectious diseases.

325

326 Findings from this study revealed a higher likelihood of good handwashing practices among 327 females than males, although it was not significant. Our finding contradicts cultural notions 328 which suggests that hygiene measures are more frequently practiced among females than males. 329 However, a few other studies have reported no difference in the practice of hand hygiene among 330 males and females in Nigeria (Ogunsola et al., 2013; Martins \& Osiyemi, 2017). The agreement 331 of our findings with reference literatures could be due to the alienation of regular and proper 332 handwashing practices in the Nigerian context. This could therefore have contributed to the 333 observed level of handwashing practices among males and females as found in this study. The 334 availability of water and sanitation access have been identified as major determinants of good 335 handwashing practices (Ogunsola et al., 2013). However, these basic amenities are not readily 336 available in many Nigerian homes (Uchejeso \& Obiora, 2020). This therefore prompts 337 overcrowding of persons at wells and boreholes, a condition which necessitates the use of water 338 in small amounts either for hand washing or other purposes. Findings from this study thus imply 
339 the need for improved access and portable water supply as required for the reduction of COVID-

34019 transmission in the communities.

341

342 We found that COVID-19 poses significant threat to local economy, resulting in low income and

343 resultant hunger. This is likely due to the increased cost of purchasing goods or a result of the

344 lockdown which has denied many individuals the opportunity to earn their income. Denial of

345 opportunities to engage in money-making ventures was experienced and impacts such as hunger

346 was greatly felt among many persons (Chukwuorji \& Iorfa, 2020). This explains the need for the

347 provision of palliatives to fight hunger and reduce susceptibility to other infections during the

348 COVID-19 outbreak. Similarly, decreased productivity and job losses and an unprecedented

349 economic disaster have been reported (Atalan, 2020). Contrary to the finding in this study, other

350 studies have reported stress and anxiety as psychological reactions due to the Coronavirus

351 pandemic (Atalan, 2020). Other psychological reactions such as boredom, anger, and loneliness

352 have been notably identified as resultant threats during the COVID-19 pandemic (Aluh \& Onu,

353 2020). This calls for the provision of psychosocial support for individuals during the COVID-19

354 lockdown. Interestingly, a recognition of the significance of essential staff has also resulted from

355 the COVID-19 outbreak (The National, 2020).

356

357 Pertaining to suggestions to the government concerning COVID-19 containment, the provision

358 of medical supplies and palliatives received highest recommendation among respondents. Most

359 Nigerian households depend on daily earnings of breadwinners, and difficulty in survival was

360 experienced during the COVID-19 lockdown which lasted for three months in Nigeria

361 (Chukwuorji \& Iorfa, 2020). Also, health education, the enforcement of preventive measures, 362 and free testing and treatment received much recognition. These imply two things. Firstly, health 363 education concerning COVID-19 should be done by public health officials in simple, 364 unambiguous languages which will facilitate the understanding of community members. 365 Secondly, the availability of medical supplies and palliatives would enhance the adherence to 366 safety measures for COVID-19, such as the use of face masks among community members. 367 Similar suggestions have been made in previous studies (Kebede et al., 2020) 
370 Strengths of the Study

371

372 Up to date, most studies on perception and practices regarding COVID-19 have used electronic 373 sources for data collection, and such results may have been biased. Our study is a community374 based physical study that used a semi-structured interviewer-administered questionnaire. To the 375 best of our knowledge, it is the first to study the perception and practices of adult population in 376 urban communities in Nigeria. The study also made use of an adequate sample size (360 adults).

377

378 Limitations of the Study

379

380

As this study was limited to the perception and practices regarding COVID-19, the knowledge of 381 community members on the illness was not addressed. The assessment of factors influencing 382 COVID-19 practices among community members was obscure in this study.

383

384

\section{Conclusions}

385

386

387

The adoption of preventive measures is critical to forestall onward transmission of COVID-19. However, adequate, and correct risk perception for COVID-19 is required to enable the adoption of COVID-19 safety measures. We hereby recommend enhanced sensitization and health education sessions for all community members about COVID-19 in Ibadan metropolis regardless of their sociodemographic characteristics. Also, health campaigns should be more focused on practices such as regular handwashing with soap and water, physical and social distancing, which protect against transmission of COVID-19 among community members irrespective of their sex. In addition, access of individuals to portable source of water supply should be enabled by increased provision of water sources in residential apartments. The government should also install more infrastructures for water supply where dearth of water exists.

396

397

\section{Acknowledgements}

The authors express their gratitude to all community members for their willingness and cooperation to participate in this study. 
401 References

402

403 ACDC. 2020. Coronavirus Disease 2019 (COVID-19). Africa Centre for Disease Control.

404 Available at: https://africacdc.org/\%20covid-19/. (accessed 25th August 2020).

405

406 Al-Hanawi MK, Angawi K, Alshareef N, Qattan AMN, Helmy HZ, Abudawood Y, Alqurashi 407 M, Kattan WM, Kadasah NA, Chirwa GC, Alsharqi O. 2020. Knowledge, Attitude, and Practice 408 Toward COVID-19 among the Public in the Kingdom of Saudi Arabia: A Cross-Sectional Study. 409 Frontiers in Public Health 8: 1-9.

410

411 Aluh DO, Onu JU. 2020. The Need for Psychosocial Support Amid COVID-19 Crises in 412 Nigeria. Psychological Trauma: Theory, Research, Practice, and Policy. Advance online 413 publication. Doi: 10.1037/tra0000704. Available at:

414 https://www.researchgate.net/publication/342372240.

415

416

Atalan A. 2020. Is the lockdown important to prevent the COVID-9 pandemic? Effects on 417 psychology, environment, and economy-perspective. Annals of Medicine and Surgery 56: 38-42.

418

419 Chukwuorji JC, Iorfa SK. 2020. Commentary on the Coronavirus Pandemic: Nigeria.

420 Psychological Trauma: Theory, Research, Practice, and Policy. 1-3. Doi: 10.1037/tra0000786.

421

422 de Zwart O, Veldhuijzen IK, Elam G, Aro AR, Abraham T, Bishop GD, Voeten HACM, 423 Richardus JH, Brug J. 2009. Perceived Threat, Risk Perception, and Efficacy Beliefs Related to 424 SARS and Other (Emerging) Infectious Diseases: Results of an International Survey. 425 International Journal of Behavioral Medicine 16: 30-40. Doi: 10.1007/s12529-008-9008-2.

Dkhar SA, Quansar R, Saleem SM, Khan SM. 2020. Knowledge, Attitude, and Practices Related 428 to COVID-19 Pandemic among Social Media Users in J\&K, India. Indian Journal of Public 429 Health 64: Suppl S2:205-210. Doi: 10.4103/ijph.IJPH_469_20.

430 
432 Gidado S, Oladimeji AM, Roberts AA, Nguku P, Nwangwu IG, Waziri NE, Shuaib F, 433 Oguntimehin O, Musa E, Nzuki C, Nasidi A, Adewuyi P, Daniel TA, Olayinka A, Odubanjo O, 434 Poggensee G. 2015. Public knowledge, perception and source of information on ebola virus 435 disease - Lagos, Nigeria; September, 2014. PLoS Currents 7: 436 ecurrents.outbreaks.0b805cac244d700a47d6a3713ef2d6db. Doi: 437 10.1371/currents.outbreaks.0b805cac244d700a47d6a3713ef2d6db.

438

439 Iorfa SK, Ottu IFA, Oguntayo R, Ayandele O, Kolawole SO, Gandi GC, Dangiwa AL, Olapegba 440 PO. COVID-19 knowledge, risk perception and precautionary behavior among Nigerians: A

441 moderated mediation approach. Preprint. Available at:

442 https://www.researchgate.net/publication/341659395.

443

444 Kebede Y, Yitayih Y, Birhanu Z, Mekonen S, Ambelu A. 2020. Knowledge, perceptions and 445 preventive practices towards COVID-19 early in the outbreak among Jimma university medical 446 center visitors, Southwest Ethiopia. PLoS ONE 15: e0233744. Doi: 447 10.1371/journal.pone.0233744.

448

449 Lichtenstein A, Ajayi R, Egbunike N. 2020. Across Africa, COVID-19 heightens tension 450 between faith and science: Some leaders reject expert advice to ban religious gatherings. 451 Available at: https:// globalvoices.org/2020/03/25/across-africa-covid-19-heightens452 tensionbetween-faith-and-sciencel. (accessed 11 August 2020).

453

454 Martins SO, Osiyemi AA. 2017. Hand hygiene practices post Ebola virus disease outbreak in a 455 Nigerian Teaching Hospital. Annals of Ibadan Postgraduate Medicine 15:16-22.

456

457 Nabi R. In: A cognitive-functional model for the effects of discrete negative emotions on 458 information processing, attitude change, and recall. Communication Theory; 1999. 9: p. 292459 320. Doi: 10.1111/j.1468-2885.1999.tb00172.x.

460

461 NCDC. 2020. COVID-19 Outbreak in Nigeria Situation Report. Abuja: Nigeria Centre for 462 Disease Control. Available at: 
463

464 (accessed on 26th August 2020).

465

466

467

468

469

470 471 2020).

472

47

474

475

476

477

478

479

480

481

482

483

484

485

486

487

488

489

490

491

492

493 15 June 2020).

(

NCDC. COVID-19 Nigeria. Nigeria Centre for Disease Control. Available at: https://covid19.ncdc.gov.ng/ (accessed on 11 August, 2020).

Nwaubani A. T. 2020. Coronavirus: Why some Nigerians are gloating about Covid-19. BBC News. Available at: https://www.bbc .com/news/world-africa-52372737 (accessed on 11 August,

Olapegba PO, Ayandele O, Kolawole SO, Oguntayo R. 2020. COVID-19 Knowledge and Perceptions in Nigeria. Preprint. Available at: https://www.researchgate.net/publication/340596815 (accessed 11 August 2020).

Ogunsola F, Balogun M, Agbeifo S, Oduyebo O, Oladele R, Olufemi J, Ajieroh V. 2013. Perception and practice of handwashing in Kuramo community, Lagos, Nigeria. International Journal of Infection Control 9:11. doi:10.3396/ijic.v9i1.006.13.

The National. 2020. Covid-19: How lockdown could affect our relationships. Available at: https://www.thenational.scot/news/18405753.covid-19-lockdown-affect-relationships/ (accessed

Tarkang EE, Zotor FB. 2015. Application of the Health Belief Model (HBM) in HIV Prevention: A Literature Review. Central African Journal of Public Health 1: 1-8.

Enwongo A. 2020. Covid-19: Oyo Confirms 56 New Cases In 13 LGAs. Available at https://thewhistler.ng/covid-19-oyo-confirms-56-new-cases-in-13-lgas/. (accessed 25 June 2020).

The Pace Setter State. 2020. War On COVID-19: Oyo Threatens To Shut Markets For Flouting Precautionary Measures. Oyo State. Available at https://oyostate.gov.ng/war-on-covid-19-oyothreatens-to-shut-markets-for-flouting-precautionary-measures/. (accessed 26 June 2020). 
494

495 Tobin EA, Asogun DA, Isah EC, Ugege OG, Ebhodaghe P 2013. Knowledge and practice of 496 infection control among primary care providers in an endemic suburban community of Edo 497 State: implications for control. Journal of Medicine and Medical Sciences 4: 311-318.

498

499

500

501

502

503

504

505

506

507

508

509

510 511 Academic, 423-450.

512

513

514

515

516

517

518

519

520

522

523

524

521 WHO. 2020. Coronavirus disease (COVID-19) advice for the public: World Health

Uchejeso OM, Obiora ER. 2020. Handwashing and personal hygiene among Nigerians in the face of COVID-19 (Coronavirus). American Journal of Biomedical Science \& Research 8. doi: 10.34297/AJBSR.2020.08.00133.

Ufuwa IS, Akpa CO, Umeokonkwo CD, Umoke M, Oguanuo CS, Olorukooba AA, Bamgboye E, Balogun MS. 2020. Knowledge and risk perception towards Lassa fever infection among residents of affected communities in Ebonyi State, Nigeria: implications for risk communication. BMC Public Health 20:1-10. Doi: /10.1186/s12889-020-8299-3.

Witte K. 1998. Fear as motivator, fear as inhibitor: Using the extended parallel process model to explain fear appeal successes and failures. In: Andersen PA, Guerrero LK (eds) The handbook of communication and emotion: research, theory, applications, and contexts. San Diego, CA:

WHO. 2020. Coronavirus disease 2019 (COVID-19) Situation Report -51 Geneva: World Health Organization. Available at: https://covid19.who.int/. (accessed 26th August 2020).

WHO. 2020. World Health Organization. Coronavirus disease (COVID-19) Situation Report149 Geneva: World Health Organization. Available at: https://www.who.int/docs/defaultsource/coronaviruse/situation-reports/20200623-covid-19-sitrep-155.pdf?sfvrsn=ca01ebe_2 (accessed 26th August 2020). Organization. https://www.who.int/emergencies/diseases/novel-coronavirus-2019/advice-forpublic (accessed 25 June 2020). 
525 Zhong B-L, Luo W, Li H-M, Zhang Q-Q, Liu X-G, Li W-T, Li Y. 2020. Knowledge, attitudes 526 and practices towards COVID19 among Chinese residents during the rapid rise period of the 527 COVID-19 outbreak: a quick online cross-sectional survey. International Journal of Biological 528 Sciences 16:1745-1752. Doi: 10.7150/ijbs.45221

529

530 
Figure 1

Practices of Ibadan residents to COVID-19 symptoms

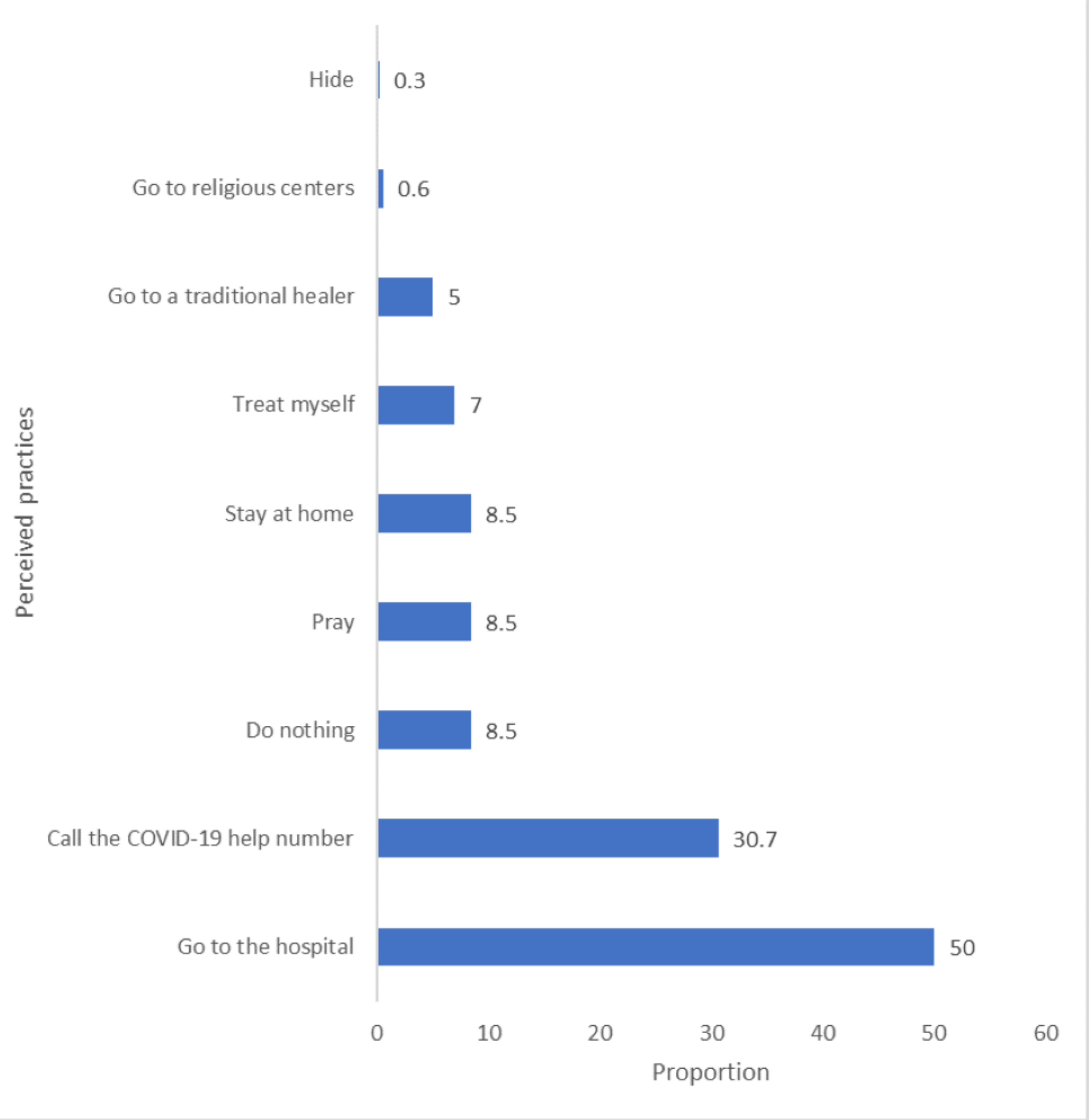


Figure 2

\section{Practices of COVID-19 prevention among respondents}

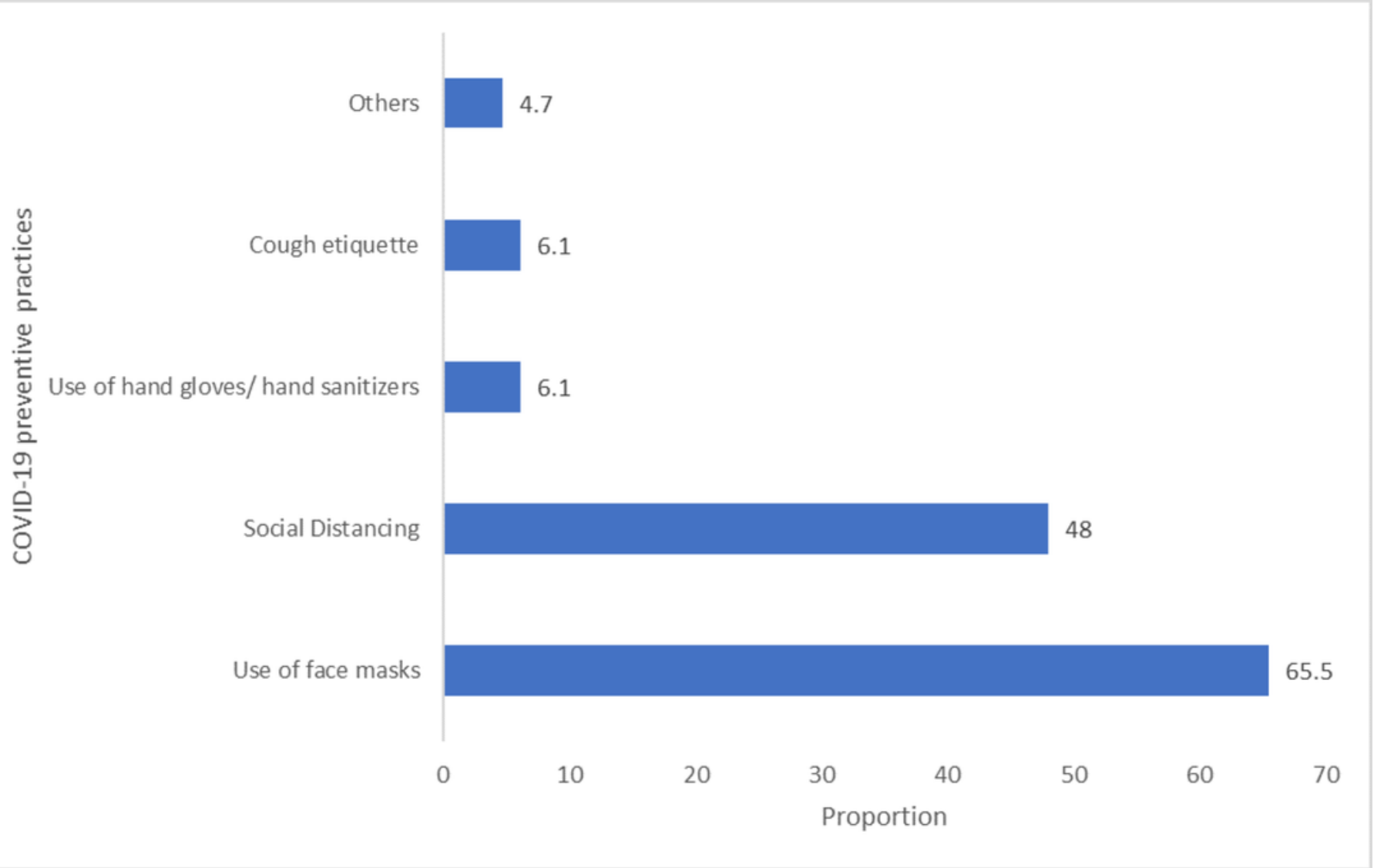


Figure 3

Points scored in handwashing demonstration

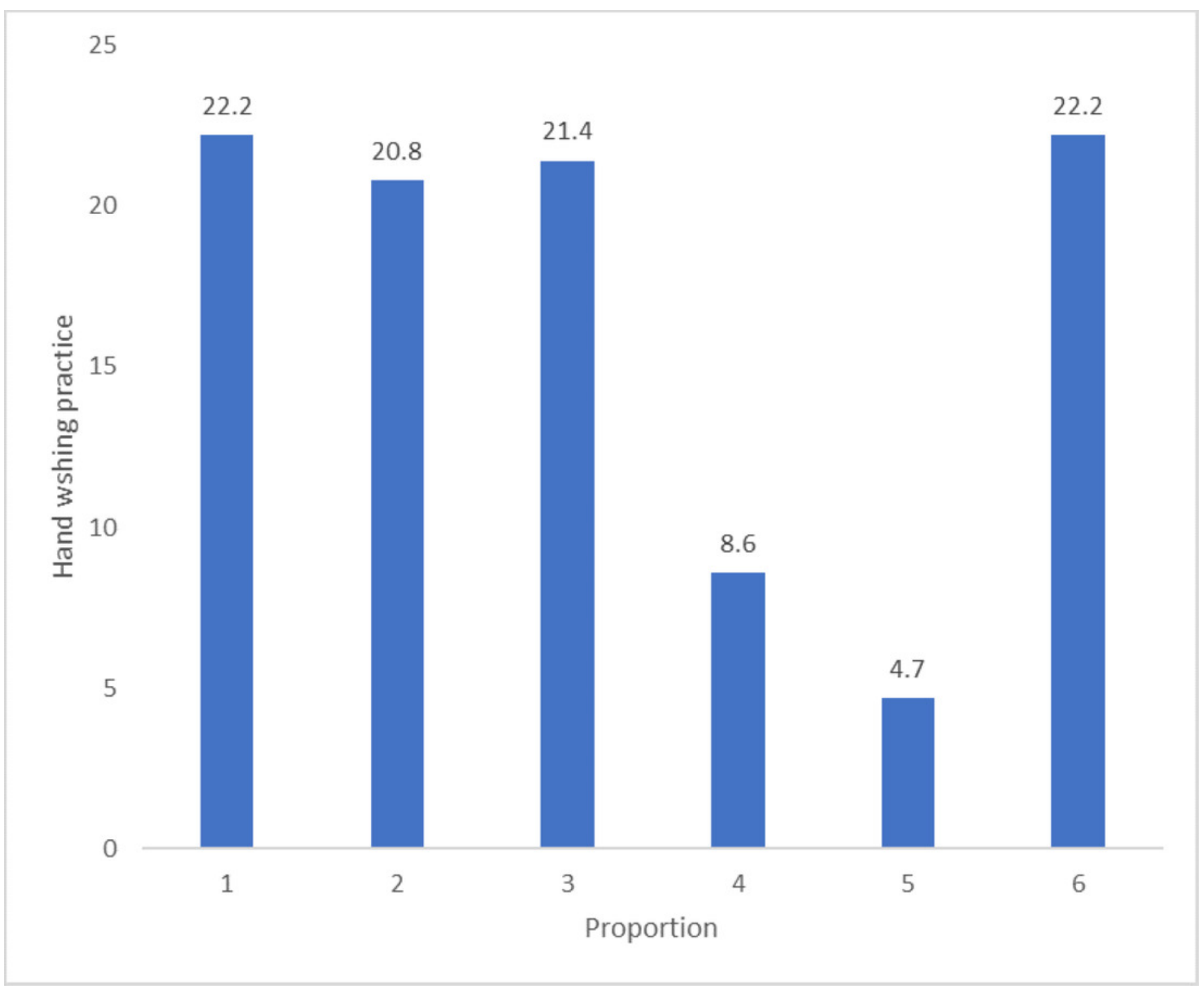




\section{Table 1 (on next page)}

Sociodemographic characteristics of respondents among Ibadan residents, 2020 
1

\begin{tabular}{|l|l|l|}
\hline Socio-demographic Characteristics & Frequency & \% \\
\hline Age group (Years) & & \\
\hline$<25$ & 70 & 19.4 \\
\hline $25-34$ & 136 & 37.8 \\
\hline $35-44$ & 106 & 29.4 \\
\hline$\geq 45$ & 48 & 13.3 \\
\hline Sex & & \\
\hline Male & 135 & 37.5 \\
\hline Female & 225 & 62.5 \\
\hline Highest level of Education & & \\
\hline Primary and below & 28 & 7.8 \\
\hline Secondary and above & 332 & 92.2 \\
\hline Ethnicity & & \\
\hline Yoruba & 314 & 87.2 \\
\hline Ibo & 31 & 8.6 \\
\hline Hausa & 8 & 2.2 \\
\hline Others & 7 & 1.9 \\
\hline Occupation & & \\
\hline Business/Trader & 171 & 47.5 \\
\hline Artisans & 110 & 30.6 \\
\hline Professional/Civil Servant & 30 & 8.3 \\
\hline Unemployed/housewife/student & 49 & 13.6 \\
\hline & & \\
\hline
\end{tabular}

2 
Table 2 (on next page)

Perceptions and effects of COVID-19 and suggestions to government by community members in Ibadan, 2020 
1

\begin{tabular}{|l|l|}
\hline Variables & n (\%) \\
\hline Perception on COVID-19 & \\
\hline It creates a lot of panic & $122(35.7)$ \\
\hline It is a deadly disease & $94(27.5)$ \\
\hline I am at risk of COVID-19 infection & $89(26)$ \\
\hline It is highly infectious & $72(21.1)$ \\
\hline It is an attack by the Western World & $68(19.9)$ \\
\hline It is just being exaggerated & $41(12)$ \\
\hline It has no cure & $33(9.6)$ \\
\hline Don't believe it exists & $28(8.2)$ \\
\hline An intention for corruption & $23(6.7)$ \\
\hline Effects of COVID-19 & \\
\hline Hunger/Low income & $167(48.8)$ \\
\hline Academic delay & $30(8.8)$ \\
\hline Restricted movement/No going to work & $25(7.3)$ \\
\hline No gatherings & $20(5.8)$ \\
\hline Suggestions to Government & \\
\hline Provide medical supplies/Palliatives/Seek cure & $108(31.6)$ \\
\hline Health Education/Enforce preventive measures & $70(20.5)$ \\
\hline Free testing/Free treatment & $68(19.9)$ \\
\hline Stop reporting false figures/Lift lockdown and bans & $44(12.9)$ \\
\hline No idea/Do anything & $27(7.9)$ \\
\hline
\end{tabular}

2

3

4 


\section{Table 3(on next page)}

Association between sociodemographic variables and practice of handwashing among community members who have heard of COVID-19 in Ibadan 2020 
1

\begin{tabular}{|l|l|l|l|l|}
\hline Sociodemographic Variable & \multicolumn{2}{l|}{ Practice of hand washing } & Chi-square & p-value \\
\hline & Good & Poor & & \\
\hline Age & n (\%) & n (\%) & & \\
\hline$<25$ & $16(23.5)$ & $52(76.5)$ & 3.890 & 0.274 \\
\hline $25-34$ & $22(16.9)$ & $108(83.1)$ & & \\
\hline $35-44$ & $19(19.6)$ & $78(80.4)$ & & \\
\hline$>44$ & $14(29.8)$ & $33(70.2)$ & & \\
\hline Sex & & & & 0.228 \\
\hline Male & $22(17.3)$ & $105(82.7)$ & 1.451 & \\
\hline Female & $49(22.8)$ & $166(77.2)$ & & \\
\hline Highest level of Education & & & & \\
\hline Primary and below & $7(26.9)$ & $19(73.1)$ & 1.109 & \\
\hline Secondary and above & $64(20.3)$ & $252(79.7)$ & & 0.775 \\
\hline Ethnicity & & & & \\
\hline Yoruba & $62(20.8)$ & $236(79.2)$ & 0.592 & \\
\hline Ibo & $6(20.7)$ & $23(79.3)$ & & \\
\hline Hausa & $1(12.5)$ & $7(87.5)$ & & \\
\hline Others & $2(28.6)$ & $5(71.4)$ & & \\
\hline Occupation & & & & \\
\hline Business/Trader & $31(19.3)$ & $130(80.7)$ & 0.915 & \\
\hline Artisans & $24(23.1)$ & $80(76.9)$ & & \\
\hline Professional/Civil Servant & $5(17.2)$ & $24(82.8)$ & & \\
\hline Unemployed/housewife/student & $11(32.9)$ & $37(77.1)$ & & \\
\hline & & & & \\
\hline
\end{tabular}

2

3

4 


\section{Table 4(on next page)}

Multivariate analysis of the determinants of good handwashing practices 
1

\begin{tabular}{|l|l|l|l|l|}
\hline \multirow{2}{*}{ Sociodemographic Variable } & \multirow{2}{*}{ AOR } & \multicolumn{2}{|c|}{ 95\%CI of AOR } & \multirow{2}{*}{ p-value } \\
\cline { 3 - 4 } & & Lower & Upper & \\
\hline Age & & & & \\
\hline$<25$ & 0.764 & 0.276 & 2.116 & 0.605 \\
\hline $25-34$ & 0.534 & 0.248 & 1.151 & 0.109 \\
\hline $35-44$ & 0.595 & 0.271 & 1.306 & 0.196 \\
\hline$>44$ & 1 & & & \\
\hline Sex & & & & \\
\hline Male & 0.725 & 0.418 & 1.259 & 0.253 \\
\hline Female & 1 & & & \\
\hline Highest level of Education & & & & \\
\hline Primary and below & 1.146 & 0.451 & 2.911 & 0.775 \\
\hline Secondary and above & & & & \\
\hline Ethnicity & & & & \\
\hline Yoruba & 1.279 & 0.534 & 3.065 & 0.581 \\
\hline Ibo & 0.750 & 0.083 & 6.735 & 0.797 \\
\hline Hausa & 1.279 & 0.534 & 3.065 & 0.581 \\
\hline Others & & & & \\
\hline Occupation & & & \\
\hline Business/Trader & & & \\
\hline Artisans & 0.933 & 0.358 & 2.434 & 0.888 \\
\hline Professional/Civil Servant & 1.619 & 0.546 & 4.804 & 0.385 \\
\hline Unemployed/housewife/student & 1 & 0.219 & 3.448 & 0.842 \\
\hline
\end{tabular}

2

3

4 